\title{
Surveys and valuations - Breach of contract and negligence
}

Received (in revised form): 2nd November, 2006

\section{Sarah Wilson LLB, ACIArb}

is an associate solicitor within Watson Burton LLP's Construction \& Engineering Department, one of the largest specialist construction legal departments outside London. Sarah's clients vary from developers and main contractors through to design professionals and sub-contractors. She specialises in large-scale, high-value engineering and construction disputes and has wide-reaching experience of various dispute resolution forums such as the Technology and Construction Court, arbitration, adjudication and mediation. She also has wide-ranging experience in drafting contracts in relation to construction and engineering projects. She is an associate of the Chartered Institute of Arbitrators and is the Treasurer of the Northumbria branch.

Correspondence: Sarah Wilson, Watson Burton LLP, 1 St James' Gate, Newcastle upon Tyne NE99 1YQ, UK; Tel: + 44 (0)191 2444336 ; Fax: + 44 (0)191 244 4500; E-mail: sarah.wilson@watsonburton.com

\begin{abstract}
This paper reviews liabilities for surveys and valuations to both clients and third parties in terms of contract and non-contractual claims. It addresses the extent of losses for which valuers and surveyors can be responsible, and provides suggestions to avoid claims emphasising the provision of a quality service to the client. The use of the term 'surveyor' in this paper is intended to refer to both surveyors and valuers.
\end{abstract}

Journal of Building Appraisal (2007) 2, 294-300. doi:10.1057/palgrave.jba.2950050

\section{Keywords:}

contract, breach, negligence, skill and care, damages, professional indemnity insurance

\section{INTRODUCTION}

It is a fact of life for all professionals, including surveyors, that work is carried out with half an eye on potential claims and the professional indemnity insurance policy. That need not be such a bad thing if the result is a disciplined approach to the performance of the work. Protective measures should result in a clearer scope of work and a happier client. To work out what measures can be taken, it is first necessary to analyse how claims can arise.

Claims against surveyors are invariably the result of one of the following two situations:

(1) where the surveyor breaches of an express or implied term of the contract with its client; or

(2) a non-contractual claim usually under the common law tort of negligence or negligent mis-statement by the client or a third party, where the third party has acted in reliance on the surveyor's report.

The distinction between tort and contract is important primarily as to who can make a claim and the losses the client will recover, and this is dealt with in more detail below, although usually claims in contract and tort are brought concurrently.

Identifying the client has often been an issue with valuations where both homeowner and lender have an interest in the property and therefore in the valuation. Even where the 
homeowner pays for the basic valuation the contractual relationship is with the lender, and the homeowner has to rely upon non-contractual remedies.

On the other hand, a contractual relationship will usually exist with the homeowner who commissions a homebuyers or structural survey.

\section{SURVEYOR'S DUTIES UNDER CONTRACT}

Providing the parties agree that a survey is to be carried out and that the surveyor is to receive payment of some kind, a contract exists. Where problems often arise is in identifying the client and also when the terms and conditions of the survey are not agreed.

\section{Implied terms}

In the worst-case scenario no terms are agreed between the surveyor and client. This is a rare situation but not unheard of. In these circumstances, the Supply of Goods and Services Act 1982 (herein referred to as SGSA) implies certain critical terms into the contract. Those terms are:

(1) That the surveyor will perform that service with reasonable care and skill - Section 12. (A duty similar to this is implied in non-contract claims at common law.) Falling below the standard of reasonable care and skill could result a claim for damages for breach of contract from the client (and/or claim under the common law in negligence from client or a third party, as discussed later). Exactly how that duty may be breached and to what extent that duty is owed is discussed below.

(2) That the service will be performed within a reasonable amount of time (SGSA, Section 14).

(3) That the client will pay a reasonable price for the survey/services provided (SGSA, Section 15).

So not stating any terms will not be fatal to a claim. The SGSA, however, does not resolve all uncertainty between surveyor and client. For example, what is a reasonable time for performance to a surveyor may not be what the client considers reasonable and the same applies to the surveyor's fees. This uncertainty increases the risk of dispute. Agreeing express contract terms at the outset means certainty for all concerned.

\section{Express terms}

A contract between surveyor and client is like any other contract in that it will almost always contain express terms, that they both agree at the time the contact is entered into.

Those terms will often be in writing although contract terms are sometimes agreed orally. Typically, survey contracts are agreed by telephone and subsequently confirmed in writing. For the avoidance of doubt (and to maintain a record for the future) it is always preferable for a contract to be in writing or alternatively, if oral, the agreed terms should be recorded in writing (preferably as a letter to the client). Indeed, RICS Practice Statement 2 requires a valuer to agree or confirm instructions before the report is issued.

The minimum terms which should be included are: price; details of the property to be surveyed; the scope of the survey undertaken by the surveyor; and the period for completion of the survey.

Surveyors should include their standard conditions of service or engagement. They must be incorporated into the contract (ie agreed at the time the contract is entered into) which will mean in the telephone conversation, in the scenario referred to above. They 
will, generally, include terms such as time for payment, interest on outstanding fees and limits on the surveyor's liability.

Also note that all exclusion clauses are subject to the 'reasonableness' test under the Unfair Contract Terms Act 1977 (UCTA). This is particularly relevant where liability is limited in scope or financially. The court will strike out a particular clause if it is unreasonable taking account of (per Lord Griffiths in Smith $v$ Bush and addressed later in this paper):

(a) the bargaining power of the parties;

(b) whether it would have been reasonably practicable to obtain advice from another source;

(c) the complexity of the task for which liability is being excluded;

(d) the practical consequences of upholding (or not) the clause; and

(e) who employed and paid the surveyor.

Care should be taken to ensure that exclusion clauses are not unreasonable, particularly when dealing with domestic properties for homebuyers. Also note that no clause should exclude liability for death or personal injury resulting from negligence, as it will automatically be void under UCTA.

Express and implied terms impose obligations on both the surveyor and client. If either fails to comply, it is a breach of contract which entitles the other to recover its losses caused by the breach as damages.

\section{Duties owed under the contract}

In the absence of agreed terms to the contrary, the surveyor will be under a duty to his client under the contract to exercise reasonable care and skill. This is measured by the actions of a reasonably competent chartered building surveyor. If there is a dispute, an independent surveyor will be required to give evidence as an expert witness, as to the actions of a reasonably competent chartered building surveyor. A similar duty is also owed in negligence whether or not excluded or limited in contract.

On the other hand, a higher standard of care may be required by the client, for example a requirement to exercise all necessary care and skill. This should always be resisted. In particular, surveyors and insurers may require notification prior to any such agreement. Failure to provide such notification could invalidate PI cover.

\section{DAMAGES PAYABLE UNDER CONTRACT}

If a surveyor is in breach of the contract, the client is entitled to damages to remedy the breach. The client will recover all losses arising naturally from the breach. In addition, such losses reasonably contemplated by both parties at the time the contract was entered into, for example, the loss of a lucrative business contract for which the surveyor was aware the building was required, may be capable of recovery.

The issue of damages was tackled in the case of BBL- $v$-Eagle Star [1997] A.C. 191. Due to the surveyor's breach of contract (and also negligence), the valuation provided was incorrect. The House of Lords awarded damages representing the difference between the valuation and the correct valuation at the time of the valuation as being the foreseeable consequence of the breach. This is the usual approach of the courts, but in certain circumstances the cost of repairs may be recoverable.

When entering into contracts, surveyors should take note of any special circumstances, for example a specific use for a property and consider restricting liability for such losses within the contract. 


\section{SURVEYORS’ DUTIES IN NEGLIGENCE}

A client or third party who wishes to make a non-contractual claim in negligence must prove:

(1) that a duty of care is owed by the surveyor;

(2) that the duty of care has been breached;

(3) that there is a causal link between the breach and the damage caused; and

(4) that the negligent conduct was likely to cause damage of the type claimed.

Further, in the case of economic loss as opposed to physical loss (surveyors negligence claims are invariably based on economic loss), it must be shown that the defendant assumed responsibility to protect the claimant from loss.

It is, however, a well-established principle that where a surveyor owes a duty of care to his client under the contract, he will also owe a concurrent duty of care to his client in the tort of negligence. Therefore, a surveyor in breach of his duty to his client can be sued for breach of contract and/or negligence.

\section{Duties owed to third parties}

The overwhelming difference between contract law and tort (negligence) is that a claim in negligence can be made by a third party. A third party is someone who does not have a contractual relationship with the surveyor (in some exceptional circumstances a third party may have contractual rights but this is not covered in this paper). As such, where a surveyor owes a duty of care in both contract and/or negligence to the client, a duty in tort may well be owed to a third party. The range of third parties a surveyor may potentially owe a duty to includes purchasers, subsequent purchasers, mortgagors and mortgagees.

Where a surveyor prepares a report for a client with the knowledge that the report will be shown to and relied upon by a third party, the surveyor will owe a duty to the third party. For example, in Cann -v-Wilson (1888) 39 Ch. D 39 valuers, instructed by a mortgagor sent the valuation to the mortgagee. The Court of Appeal found that the surveyor owed a duty of care in negligence to the mortgagee.

In Smith -v-Eric S Bush (A Firm) [1990] 1 A.C. 831 (Smith-v-Bush), a surveyor contracted with a lender to survey a small domestic dwelling and the lender forwarded the report to the borrower, which contained a disclaimer of liability to the borrower for the accuracy of the report and recommended the borrower obtain independent advice. When the borrower later discovered defects, an action in negligence was brought against the surveyor who relied upon the disclaimer limiting their duty to the borrower. The House of Lords, however, held that a duty of care was owed to the borrower striking out the disclaimer under UCTA 1977 on the basis it was unreasonable.

The property in Smith-v-Bush was a small, lower end of the market domestic property and the courts have been much more willing to uphold clauses limiting liability in respect of valuations where they involve commercial properties or unusual or expensive domestic properties. In Omega Trust Co. Ltd-v-Wright Son \& Pepper [1997] P.N.L.R 424, the Court of Appeal upheld a disclaimer contained in a valuation commissioned by financers in respect of three commercial retail properties. The disclaimer excluded liability to anyone except the financers, but was nevertheless relied on by separate lenders. The Court of Appeal concluded that it upheld the disclaimer as being reasonable against the separate lenders.

When surveyors enter into contracts with client, they not only need to consider the instructions received from their client, they must also consider who may reasonably rely 
on their advice. Attempts to limit or exclude liability in respect of third parties relying upon their advice may be invalid depending upon individual circumstances. It is, however, crucial that the surveyor considers limiting its liability in respect of third parties prior to entering any contract.

\section{Standard of care and skill}

A surveyor must not act 'in a way which no surveyor of ordinary skill would be guilty of, if acting with ordinary care' (Strover-v-Harrington [1988] Ch. 390). A surveyor may be negligent for failure to follow accepted professional practice. Lack of experience is no defence. All surveyors are judged against the standard of the average-skilled surveyor. Surveyors must also keep themselves up to date with developments in their profession, to avoid the risk of falling below the accepted standard.

Irrespective of the standard of care, the extent of the surveyor's duty will depend on the instructions received which the surveyor must carefully consider in terms of what they are asked to do.

\section{Valuations}

A surveyor is not necessarily responsible for overvaluation of a property; however, gross overvaluation is strong evidence in demonstrating a breach by the surveyor. The decision in Baxter-v-F. W. Gapp \& Co [1939] 2 All ER 752 provided guidance in respect of valuations stipulating a careful investigation of the property in which all relevant inquiries are pursued; a skilful interpretation of the facts disclosed; and a well-practised method of conclusion.

Case law has sought to establish a margin for error known as the bracket to evidentially assist in deciding whether the valuation can be negligent. Singer \& Friedlander-v-John D Wood \& Co 2 E.G.L.R 84 suggested that an error of 10 per cent on either side of the correct figure is permissible, and in exceptionally difficult cases a figure of 15 per cent might be used. Evidence that the surveyor's valuation fell outside the bracket does not by itself prove that the surveyor acted negligently if he, in fact, exercised reasonable skill and care in carrying out the valuation. The simple fact that he was wrong does prove that he was negligent. Recent case law has shown that the bracket used by the courts usually fall somewhere between the 10 and 20 per cent margin.

\section{Failure to observe defects}

Liability for failure to carry out an adequate inspection of the property and/or observe a material defect in property will be established if:

(1) a reasonably competent and experienced surveyor would have observed and reported the defect; and

(2) the defect is the sort of defect which ought to have been discovered by the type of survey the surveyor was instructed to carry out.

(Stewart-v-H.A. Brechin \& Co (1959) S.C. 306)

A surveyor's failure to observe a particular defect may be due to the surveyor failing to inspect a particular part of the property. In deciding whether the surveyor is responsible, the scope of the instructed survey must be examined to identify whether an inspection of the area of the property in question ought to have formed part of the survey carried out. Surveyors, therefore, should always make it clear (in writing) if any areas of the property or items are excluded from the survey. 
The scope of a survey may also require the surveyor to investigate further by uncovering and opening up specific areas of the property. The requirement to open up or uncover will depend on the instructions given and whether there is visible evidence of suspicious areas. The practicality of opening or uncovering the affected area will also be taken into consideration. Again, surveyors should notify the client (in writing) if such investigation is excluded from the survey.

Finally, although a surveyor may inspect the entire property in accordance with instructions, he may find himself in breach for failure to observe the existence of defects. Examples of circumstances where surveyors have been responsible for such failure include a large number of cases where the surveyor has failed to identify visible signs of dry rot, woodworm, subsidence and cracking in circumstances where an ordinary competent surveyor would have so identified.

\section{DAMAGES IN NEGLIGENCE}

A client or a third party who wishes to pursue a claim in negligence against a surveyor will have to prove that he suffered damage as a result of the surveyor's negligent advice. Usually, the claimant will have to demonstrate that he relied on the surveyor's report in deciding to purchase the property, or in the case of lender lent money in reliance of the report. The claimant will have to prove that had he been properly informed he would not have acted as he did. For example, had the claimant been properly informed, he would have been in a position to renegotiate the price of the property to reflect defects in property or alternatively he would not have purchased the property.

Generally, the level of damages in surveyor's negligence cases will not be the cost of repairing the undiscovered defects. Damages will usually be the difference between the price paid for the property and true market value of the property at the time the advice was received. Additional damages such as the cost of temporary accommodation for an uninhabitable dwelling; overpayment of stamp duty; or even the cost of buying a new property if the dwelling is entirely uninhabitable may be recovered providing the claimant can show that those losses are not too remote. Such damage is likely to be foreseeable in situations concerning surveys of domestic property.

\section{Practical advice and comment}

- Ensure as a minimum, the crucial contract terms are agreed and documented; price, timescale, scope of work, extent of survey and exclusions from the survey/valuation.

- Ensure that any exclusions are clearly stated in writing, for example areas of the property, specific types of defects or investigation.

- Consider expressly limiting liability for losses.

- Be aware of any 'special losses' a client may sustain. For example, a specific contract which could be lost in the event of a negligent survey.

- Check the standard of care required and strongly resist any higher standard than reasonable care and skill.

- Ensure standard terms and conditions are incorporated into the contract.

- Ensure that instructions are documented and confirmed to the client. This avoids scope for misunderstanding.

- Ensure compliance with PI policy.

- Be aware of any third parties (eg lenders) who may rely upon the survey and seek to exclude. 
- Ensure adequately qualified and experienced personnel carry out the work.

- Adhere to professional standards and guidance.

- Notify professional indemnity insurers as soon as any claim is suspected/intimated. Failure to do so could allow the insurers to avoid or limit the policy.

- A claim in contract can be made up to 6 years after the breach (12 years where the contract is a deed). A claim in negligence can be made up to 6 years from the date of damage (eg the date that a purchaser exchanged contracts on a property or the date on which the lender agreed to provide funds), but this can be extended to 3 years from the date of discoverability. Documentation is crucial to defend any claim brought several years after the work was carried out (when memories will have inevitably faded).

\section{CONCLUSION}

There is a perception that being overly contractual at the start of a relationship sets the wrong tone with the client. This, however, need not be so. It is in both parties' interests to know exactly where they stand and what they should expect. The alternative is potential litigation to determine the responsibilities and liabilities of the parties. This is timeconsuming and expensive but more importantly it damages the relationship, often beyond repair. It also damages the reputation of the profession generally.

Careful agreement and preparation on the basis upon which the survey or valuation is to be carried ensures each party knows what to expect and therefore reduces the risk of a dispute and litigation, and increases the possibility that the client will be happy with the service provided.

\section{Disclaimer}

This paper is designed to alert professionals. It cannot nor is it designed to replace the need for advice on specific issues or circumstance. 